\title{
ANALISIS MANAJEMEN LABA DAN KINERJA KEUANGAN PERUSAHAAN PENGAKUISISI SEBELUM DAN SESUDAH AKUISISI
}

\author{
Tyasshela Sani Wibowo \\ Department of Management FEB UMM \\ E-mail: shelasani12@yahoo.com
}

\begin{abstract}
This study discuss about earnings management and financial performance of the acquirer before and after acquisition. The purpose of research was to obtain empirical evidence of how earning management have done by acquirer companies before the implementation of acquisition. In addition it aims to determine the changes in the acquirer's financial performance before and after the acquisition. This research is a comparative study which to compare the financial performance the acquirer before and after the company make acquisition. Analysis of financial performance uses financial rations, including profitability, activity, and solvability. Analysis of earnings management using the theory of Jones modified. Earnings management by the acquirer is a proxy for discretionary accruals (DA). The company performance was measured by using financing rations (a net profit margin, return on assets, total assets turnover, and debt to equity ratio). The result of analysis showed that there are two companies which have positive discretionary accrual value and the other three companies which have negative discretionary accrual value. Moreover financial performance of the acquirer company is experiencing the different more toward to reduction of financial performance. The conclusion was that earning management of two acquirer companies (ANTM and UNTR) have done by increasing the profit (income increasing accruals) before doing the acquisition. While, the other three companies (ENRG, RAJA, and SMGR) have done earning management by decreasing the profit (income decreasing accruals) before doing the acquisition. Furthermore, financial performance that measure with NPM and DER increased after acquisition, while ROA and TATO decreased after acquisition.
\end{abstract}

Keyword: Earning Management, Acquisition, Financial Performance

\section{PENDAHULUAN}

Perkembangan zaman yang begitu pesat menyebabkan banyaknya persaingan usaha. Hal ini mendorong pihak mana-jemen perusahaan untuk mengembangkan usahanya melalui salah satu strategi bisnis jangka panjang yaitu melalui peng-gabungan usaha. Akuisisi merupakan pembelian mayoritas saham sebuah perusahaan oleh individu ataupun organisasi. Akuisisi dimaksudkan agar perusahaan yang diakuisisi dapat di-maksimalkan sumber dayanya untuk kepentingan perusahaan utama dan kepentingan perusahaan yang diakuisisi tersebut. Kontroversi muncul dibalik peristiwa akuisisi, berbagai bentuk 
rekayasa di-lakukan oleh perusahaan pengakuisisi misalnya untuk menghindari pajak, menggelembungkan nilai aset perusahaan, dan mengurus manajemen perusahaan yang dikuasai. Dalam pelaksanaan akuisisi terdapat satu tindakan yang mendukung adanya manajemen laba yang dilakukan oleh perusahaan pengakuisisi.

Manajemen laba merupakan campur tangan manajemen dalam proses pe-nyusunan laporan keuangan eksternal guna mencapai tingkat laba tertentu dengan tujuan untuk menguntungkan dirinya sendiri. Pencapaian laba tersebut muncul karena metode akuntansi memberikan peluang bagi manajemen untuk mencatat suatu fakta tertentu dengan cara yang berbeda dan peluang bagi manajemen untuk melibatkan subyektivitas dalam menyusun estimasi (Hadri dan Udiana: 2004: 3).

Tabel 1. Kinerja Keuangan Perusahaan Pengakuisisi Sebelum Akuisisi

\begin{tabular}{|c|c|c|c|c|c|c|}
\hline No & Perusahaan & Tahun & NPM & ROA & TATO & DER \\
\hline \multirow[t]{2}{*}{1} & ANTM & 2007 & 0.42 & $42 \%$ & 0.99 & 0.37 \\
\hline & & 2008 & 0.14 & $13 \%$ & 0.93 & 0.26 \\
\hline \multirow[t]{2}{*}{2} & ENRG & 2007 & 0.1 & $1 \%$ & 0.12 & 1.79 \\
\hline & & 2008 & -0.01 & $-1 \%$ & 0.14 & 2.39 \\
\hline \multirow[t]{2}{*}{3} & RAJA & 2008 & 0.01 & $1 \%$ & 0.21 & 0.01 \\
\hline & & 2009 & -0.01 & $1 \%$ & 0.21 & 0.01 \\
\hline \multirow[t]{2}{*}{4} & UNTR & 2009 & 0.13 & $15 \%$ & 1.19 & 0.75 \\
\hline & & 2010 & 0.1 & $13 \%$ & 1.25 & 0.83 \\
\hline \multirow[t]{2}{*}{5} & SMGR & 2010 & 0.25 & $23 \%$ & 0.92 & 0.28 \\
\hline & & 2011 & 0.24 & $20 \%$ & 0.83 & 0.34 \\
\hline
\end{tabular}

Dari kelima perusahaan pengakuisisi tersebut, empat perusahaan memiliki kinerja keuangan yang buruk dan satu perusahaan mempunyai kinerja keuangan yang stabil. Jadi dapat disimpulkan bahwa kelima perusahaan tersebut cenderung memiliki kinerja keuangan yang buruk sehingga hal ini mendorong perusahaan tersebut untuk melakukan manajemen laba sebelum akuisisi agar dapat menaikkan kinerja keuangannya ditahun yang akan datang. Yang melatar belakangi penelitian ini adalah bagaimana manajemen laba peru-sahaan pengakuisisi sebelum akuisisi dilakukan serta untuk mengetahui bagaimana kinerja keuangan perusahaan pengakuisisi sebelum dan sesudah akuisisi. Berdasarkan hasil penelitian diatas diperoleh perbedaan hasil (research gap) yang dilakukan oleh para peneliti sehingga penelitian ini diberi judul "Analisis Manajemen Laba dan Kinerja Keuangan Perusahaan Pengakuisisi Sebelum dan Sesudah Akuisisi".

\section{TINJAUAN PUSTAKA}

Penelitian I Putu Adnyana Usadha dan Gerianta Wirawan Yasa (2009) dengan judul Analisis Manajemen Laba dan Kinerja Keuangan Perusahaan Pengakuisisi Sebelum dan Sesudah Merger dan Akuisisi Di Bursa Efek Indonesia Tahun 2001-2002 menunjukkan bahwa perusahaan pengakuisisi melakukan tindakan manajemen laba sebelum pelaksanaan merger dan akuisisi dengan cara income increasing accrual dan hal tersebut memicu penurunan kinerja perusahaan setelah merger dan akuisisi.

Penelitian yang dilakukan Annisa Meta (2010) dengan judul Analisis Manajemen Laba dan Kinerja Keuangan Perusahaan Pengakuisisi Sebelum dan Sesudah Akuisisi yang Terdaftar di BEI Tahun 2008-2009 membuktikan bahwa tidak ada indikasi manajemen laba sebelum merger dan akuisisi yang dilakukan dengan income increasing accruals. Kinerja keuangan 
perusahaan yang diukur dengan rasio TATO mengalami kenaikan sesudah merger dan akuisisi, sedangkan NPM dan ROA mengalami penurunan sesudah merger dan akuisisi.

Penelitian Lia Aisa dan Indarto (2012) dengan judul Analisis Manejemen Laba dan Kinerja Keuangan Sebelum dan Sesudah Merger dan Akuisisi pada Perusahaan Pengakuisisi yang Terdaftar Di Bursa Efek Indonesia Tahun 2007-2009 menghasilkan adanya indikasi manajemen laba di sekitar merger dan akuisisi. Dan kinerja keuangan perusahaan yang diukur dengan $C R, D E R, R O I, R O E$ tidak menunjukkan perbedaan yang signifikan dibandingkan sebelum dan sesudah akuisisi. Tapi NPM dan TATO terdapat perbedaan yang signifikan sebelum dan sesudah merger dan akuisisi.

Sugiri dalam Widyaningdyah (2001: 92) membagi manajemen laba dalam dua definisi yaitu dalam arti sempit dan dalam arti luas. Dalam arti sempit, manajemen laba sebagai perilaku manajer untuk "bermain" dengan komponen discretionary accruals dalam menentukan besarnya earnings. Dalam arti luas, manajemen laba merupakan tindakan manajer untuk meningkatkan (menurunkan) laba yang dilaporkan saat ini atas suatu unit, dimana manajer bertanggung jawab tanpa mengakibatkan peningkatan (penurunan) profitabilitas ekonomis jangka panjang unit tersebut. Scott (2003: 352) menjelaskan motivasi dari para manajer dalam melakukan manajemen laba adalah Motivasi bonus, Motivasi kontrak, Motivasi politik, Motivasi perpajakan , Pergantian CEO, Penawaran saham Perdana.

Scott (2003: 383) dalam Meta (2010: 23) mengungkapkan bentuk- bentuk manajemen laba yang dapat dilakukan oleh manajer. Taking a bath, Income minimization, Income maximization, Income smoothing

Secara umum ada 3 pendekatan yang telah dihasilkan para peneliti untuk mendeteksi manajemen laba, yaitu (Sulistyanto: 2008: 211), Model berbasis aggregate accruals yang dikembangkan oleh Healy (1985), De Angelo (1986), Jones (1991), serta Dechow, Sloan dan Sweeney (1995). Model yang berbasis specific accruals yang dikembangkan oleh Mc Nichols dan Wilson (1988), Petroni (1992), Beaver dan Engel (1996), Beneish (1997), serta Beaver dan Mc Nichols (1998).

Model distribution of earnings yang dikembangkan oleh Burgatler dan Dichey (1997), Degeorge, Patel, dan Zechauser (1999), serta Myers dan Skinner (1999). Sejauh ini hanya model berbasis agregate accruals yang diterima secara umum sebagai model yang memberikan hasil paling kuat dalam mendeteksi manajemen laba. Alasannya, model ini sejalan dengan basis akuntansi akrual yang selama ini banyak dipergunakan karena komponen akrual yang sangat mudah untuk dipermainkan besar kecilnya.

Model Jones dimodifikasi (Modified Jones Model) merupakan modifikasi dari model Jones yang didesain untuk mengeliminasi kecenderungan untuk menggunakan perkiraan yang bisa salah dari model Jones untuk menentukan discretionary accruals ketika melebihi arah pendapatan. Model ini banyak digunakan dalam penelitian-penelitian akuntansi karena dinilai merupakan model yang paling baik dalam mendeteksi manajemen laba dan memberikan hasil paling kuat. 
Dalam Modified Jones Model komponen total accruals dapat dipisahkan menjadi 2, yaitu discretionary accruals dan non discretionary accruals. Dis-cretionary accruals memanfaatkan kebebasan dan fleksibelitas dalam menentukan nilai estimasi pada metode akuntansi. Non discretionary accruals diperoleh secara alami dari pencatatan akuntansi.

Kinerja keuangan adalah penentuan ukuran-ukuran tertentu yang dapat mengukur keberhasilan suatu organisasi atau perusahaan dalam menghasilkan laba (Sucipto: 2003: 2). Analisis time series adalah analisis perbandingan data dengan data keuangan periode sebelumnya dari tahun ke tahum (perbandingan dengan data historis). Analisis rasio keuangan meru-pakan analisis dengan membandingkan satu pos laporan keuangan dengan pos laporan keuangan lainnya, baik secara individu maupun bersama-sama guna mengetahui hubungan diantara pos tertentu, baik dalam neraca maupun dalam laporan laba rugi (Jumingan: 2006: 242). Adapun jenis-jenis rasio keuangan yang dapat digunakan untuk menilai kinerja keuangan perusahaan adalah, Rasio profitabilitas, Net Profit Margin (NPM) adalah rasio yang menunjukkan kemampuan perusahaan dalam menghasilkan keuntungan bersih. Return On Assets adalah rasio untuk menilai seberapa besar tingkat pengembalian dari aset yang dimiliki perusahaan. Rasio aktivitas, Total Assets Turnover digunakan untuk mengestimasi be-sarnya total harta atas dasar ramalan penjualan. Rasio solvabilitas, Debt to Equity Ratio adalah rasio untuk melihat berapa besarnya hutang lancar dan hutang jangka panjang operasi dibandingkan dengan modal perusahaan. Rasio likuiditas, menunjukkan hubu-ngan antara kas perusahaan dan aktiva lancar lainnya dengan hutang lancar.

Akuisisi adalah pembelian suatu perusahaan oleh perusahaan lain atau oleh kelompok investor. Akuisisi yaitu mem-peroleh atau membeli perusahaan lain dengan cara membeli sebagian besar saham dari perusahaan sasaran (Hitt: 2002: 259). Beberapa perusahaan melakukan akuisisi karena adanya beberapa motivasi. Husnan (1998: 658660) menjelaskan motivasi akuisisi adalah Sinergi, Peningkatan pendapatan, Penurunan biaya, Penghematan pajak, Diversifikasi.

\section{METODE PENELITIAN}

Jenis penelitian ini merupakan jenis penelitian komparatif yaitu penelitian yang bersifat membandingkan. Populasi dalam penelitian ini adalah tujuh perusahaan yang melakukan akuisisi mulai tahun 2009 sampai dengan tahun 2012. Terdapat lima perusahaan yang dijadikan sampel dalam penelitian ini dengan kriteria, Perusahaan publik yang tercatat di Bursa Efek Indonesia dan melakukan akuisisi antara tahun 2009 sampai dengan tahun 2012. Perusahaan termasuk industri manufaktur dan industri lain selain kelompok perusahaan yang bergerak dalam bidang asuransi dan dibidang finance atau perusahaan perbankan dan lembaga keuangan keuangan lainnya. Perusahaan memiliki tanggal akuisisi yang jelas. Menerbitkan laporan keuangan secara lengkap selama dua tahun sebelum akuisisi dan dua tahun sesudah akusisi periode berakhir per 31 Desember.

Jenis data yang digunakan adalah jenis data kuantitatif. Sumber data yang digunakan adalah sumber data 
sekunder.

Metode pengumpulan data dalam penelitian ini adalah metode dokumentasi. Manajemen Laba Langkah-langkah dalam analisis data ini adalah mencari nilai total accrual yang akan dijadikan dasar dalam mencari nilai discretionary accrual dan non dis-cretionary accrual. Berdasarkan rumus yang ada maka akan diperoleh nilai discretionary accrual dan non dis-cretionary accrual perusahaan baik sebelum perusahaan melakukan akuisisi maupun sesudah perusahaan melakukan akuisisi.

Nilai discretionary accrual dan

non discretionary accrual akan dibandingkan diantara kedua parameter tersebut akan diketahui nilai mana yang dominan terhadap masing-masing perusahaan. Langkah selanjutnya setelah nilai discretionary accrual dan non dis-cretionary accrual diketahui maka akan diperoleh satu kesimpulan bagaimana manajemen laba dilakukan oleh peru-sahaan pengakuisisi sebelum akuisisi.

Kinerja Keuangan (Analisis Rasio Keuangan)Peneliti mencari nilai rasio keuangan yang sudah ditetapkan sebagai variabel yaitu profitabilitas, aktivitas, dan solvabilitas sebelum akuisisi dan sesudah akuisisi secara time series dari tahun ke tahun, tujuannya untuk memperoleh hasil kinerja keuangan perusahaan pengakuisisi apakah mengalami peningkatan atau penurunan.

Dari hasil tersebut maka akan diperoleh suatu kesimpulan mengenai kinerja keuangan perusahaan pengakuisisi tersebut selama dua tahun sebelum dan dua tahun sesudah melakukan akuisisi.

\section{HASIL PENELITIAN DAN PEMBAHASAN}

Berdasarkan hasil penelitian terdapat lima perusahaan yang memenuhi syarat untuk dijadikan sampel dalam penelitian sebagai berikut:

Tabel 2. Data Perusahaan Akuisisi Tahun 2009-2012

\begin{tabular}{|r|r|r|r|}
\hline No & Waktu & Kode & Keterangan \\
\hline 1 & 7 Juli 2009 & ANTM & $\begin{array}{r}\text { PT. Cibaliung Sumberdaya kedalam } \\
\text { PT. Aneka Tambang Tbk. }\end{array}$ \\
\hline 2 & 5 Nopember 2009 & ENRG & $\begin{array}{r}\text { Masela Psc (Inpex Masela Ltd) kedalam } \\
\text { Energi Mega Persada Tbk. }\end{array}$ \\
\hline 3 & 24 Juni 2010 & RAJA & PT. Triguna Internusa Pratama kedalam \\
\hline 4 & 26 Agustus 2011 & UNTR & Pukun Raharja Tbk. Agung Bara Prima kedalam PT. United \\
\hline 5 & 14 Nopember 2012 & SMGR & Thanglong Cement Joint Stock Company \\
\hline
\end{tabular}

Tabel 3. Perhitungan Manajemen Laba

\begin{tabular}{|c|c|c|c|c|c|c|c|c|c|}
\hline \multirow[t]{2}{*}{ Perusahaan } & \multirow[t]{2}{*}{ Variabel } & \multicolumn{8}{|c|}{ Tahun } \\
\hline & & 2007 & 2008 & 2009 & 2010 & 2011 & 2012 & 2013 & 2014 \\
\hline \multirow[t]{2}{*}{ ANTM } & DA & 0.29 & 0.23 & - & -0.27 & 0.35 & - & - & - \\
\hline & NDA & 0.44 & 0.21 & - & -8.8 & 0.7 & - & - & - \\
\hline \multirow[t]{2}{*}{ ENRG } & $\mathrm{DA}$ & -0.41 & -0.07 & - & 0.51 & -0.57 & - & - & - \\
\hline & NDA & -61.53 & -38.29 & - & 113.15 & -83.83 & - & - & - \\
\hline \multirow[t]{2}{*}{ RAJA } & DA & - & -7.34 & -4.06 & - & -8.27 & -1.53 & - & - \\
\hline & NDA & - & -0.13 & 2.37 & - & -8.18 & -1.61 & - & - \\
\hline \multirow[t]{2}{*}{ UNTR } & DA & - & - & -1.28 & 1.45 & - & -0.55 & -7.42 & - \\
\hline & NDA & - & - & -2.33 & 1.75 & - & -1.19 & -6.45 & - \\
\hline \multirow[t]{2}{*}{ SMGR } & DA & - & - & - & 0.27 & -0.46 & - & -0.69 & -1.14 \\
\hline & NDA & - & - & - & -5.97 & -0.71 & - & -0.86 & -1.66 \\
\hline
\end{tabular}

Berdasarkan data diatas dapat diketahui bahwa perhitungan manajemen laba perusahaan pengakuisisi antara discretionary accruals dan non dis-cretionary accruals berbeda dan cenderung lebih tinggi nilainya non discretionary accruals. Dari data diatas diperoleh dua perusahaan yang melakukan manajemen laba dengan menaikkan laba perusahaan atau nilai perhitungannya lebih besar (positif) sebelum akuisisi dibandingkan dengan sesudah akuisisi. Dan ada tiga perusahaan yang melakukan manajemen laba dengan menurunkan laba laba atau nilai perhitungannya adalah negatif sebelum akuisisi dilakukan. Berdasarkan hasil perhitungan pada tabel 4 diatas, maka dapat diperoleh 
Tabel 4. Perbandingan Rasio Keuangan Sebelum dan Sesudah Akuisisi

\begin{tabular}{|c|c|c|c|c|c|c|c|c|c|c|}
\hline No & Perusahaan & Rasio & 2007 & 2008 & 2009 & 2010 & 2011 & 2012 & 2013 & 2014 \\
\hline \multirow[t]{4}{*}{1} & ANTM & NPM & 0.42 & 0.14 & Akuisisi & 0.19 & 0.18 & - & - & - \\
\hline & & ROA & $42 \%$ & $13 \%$ & & $13 \%$ & $12 \%$ & - & - & - \\
\hline & & TATO & 0.99 & 0.93 & & 0.71 & 0.68 & - & - & - \\
\hline & & DER & 0.37 & 0.26 & & 0.27 & 0.41 & - & & \\
\hline \multirow[t]{4}{*}{2} & ENRG & NPM & 0.1 & -0.01 & Akuisisi & 0.05 & 0.08 & - & - & - \\
\hline & & ROA & $1 \%$ & $-1 \%$ & & $-1 \%$ & $1 \%$ & - & - & - \\
\hline & & TATO & 0.12 & 0.14 & & 0.1 & 0.12 & - & - & - \\
\hline & & DER & 1.79 & 2.39 & & 0.99 & 1.82 & - & - & - \\
\hline \multirow[t]{4}{*}{3} & RAJA & NPM & & 0.01 & -0.01 & Akuisisi & 0.03 & 0.06 & - & - \\
\hline & & ROA & & $1 \%$ & $1 \%$ & & $2 \%$ & $5 \%$ & & \\
\hline & & ТАTO & - & 0.21 & 0.21 & & 0.93 & 0.85 & - & - \\
\hline & & DER & - & 0.01 & 0.01 & & 3.64 & 1.28 & & - \\
\hline \multirow[t]{4}{*}{4} & UNTR & NPM & - & & 0.13 & 0.1 & Akuisisi & 0.1 & 0.09 & - \\
\hline & & ROA & - & - & $15 \%$ & $13 \%$ & & $11 \%$ & $8 \%$ & - \\
\hline & & TATO & - & - & 1.19 & 1.25 & & 1.11 & 0.88 & - \\
\hline & & DER & - & - & 0.75 & 0.83 & & 0.55 & 0.6 & \\
\hline \multirow[t]{4}{*}{5} & SMGR & NPM & & - & - & 0.25 & 0.24 & Akuisisi & 0.21 & 0.2 \\
\hline & & ROA & - & - & - & $23 \%$ & $20 \%$ & & $17 \%$ & $16 \%$ \\
\hline & & TATO & - & - & - & 0.92 & 0.83 & & 0.79 & 0.78 \\
\hline & & DER & & - & - & 0.28 & 0.34 & & 0.41 & 0.37 \\
\hline
\end{tabular}

hasil bahwa dua perusahaan memiliki kinerja keuangan yang baik yaitu ENRG dan RAJA.

Sedangkan tiga perusahaan lainnya yaitu ANTM, UNTR, dan SMGR memiliki kinerja keuangan yang buruk karena nilai dari masing-masing rasio cenderung mengalami penurunan sesudah akuisisi.

Perbandingan nilai antara discretionary accruals dan non discretionary accruals dari tahun sebelum akuisisi dengan tahun sesudah akuisisi dapat digunakan sebagai dasar untuk melihat nilai total akrual yang menurut teori Jones itu bisa dimanipulasi. Perbedaan nilai antara discretionary acrruals dan non discretionary accruals disebabkan nilai total akrual perusahaan pengakuisisi berbeda. Jika nilai total akrual negatif itu artinya perusahaan pengakuisisi tidak melakukan manajemen laba, karena nilai total akrual negatif itu disebabkan oleh nilai net income yang rendah dibandingkan dengan nilai operational cash flow perusahaan. Nilai discretionary accruals yang lebih tinggi (positif) antara sebelum akuisisi dengan sesudah akuisisi itu membuktikan bahwa perusahaan melakukan manajemen laba dengan menaikkan laba perusahaan seperti mempengaruhi jumlah depresiasi atau pendapatan. Perubahan pendapatan mempengaruhi perubahan akrual yang berasal dari modal kerja seperti piutang dan utang. Perubahan pendapatan digunakan sebagai variabel kontrol karena relatif objektif sebagai ukuran operasi perusahaan sebelum manipulasi oleh manajer. Namun, tidak sepenuhnya perubahan pendapatan adalah objektif, karena tetap bisa melakukan manajemen laba melalui manipulasi pendapatan seperti percepatan pengiriman barang agar perusahaan dapat mengakui pendapatan lebih awal.

Berdasarkan perhitungan diatas, ANTM dan UNTR memiliki nilai discretionary accruals sebelum akuisisi yang lebih tinggi dibandingkan dengan sesudah akuisisi dan nilai DA sebelum akuisisi adalah positif. Jadi dapat diartikan bahwa dua perusahaan ini terbukti melakukan manajemen laba dengan menaikkan laba perusahaan sebelum akuisisi.

ENRG memiliki nilai discretionary accruals sebelum akuisisi yang lebih kecil dibandingkan dengan sesudah akuisisi. Sedangkan RAJA dan SMGR memiliki nilai discretionary accruals negatif pada periode sebelum akuisisi dan hasilnya juga tetap negatif pada periode sesudah akuisisi. Hal ini menunjukkan bahwa ketiga perusahaan ini terbukti melakukan manajemen laba dengan menurunkan laba perusahaan sebelum akuisisi.

Berdasarkan perhitungan diatas, diketahui perbandingan nilai NPM, ROA, TATO, dan DER dari sebelum akuisisi dan sesudah akuisisi. Nilai NPM dari ANTM naik, ROA turun, TATO turun, dan DER naik. Untuk ENRG, nilai NPM naik, ROA naik, TATO turun, dan DER turun. Nilai NPM dari RAJA naik, ROA naik, TATO naik, dan DER naik. NPM dari UNTR turun, ROA turun, TATO turun, dan DER 
turun. Untuk SMGR, NPM turun, ROA turun, TATO turun, dan DER naik.

Jadi, dapat disimpulkan bahwa kinerja keuangan ENRG dan RAJA sesudah akuisisi menunjukkan hasil yang semakin baik dibandingkan dengan sebelum akuisisi dilakukan. Sedangkan untuk kinerja keuangan ANTM, UNTR, dan SMGR sesudah akuisisi justru semakin buruk dibandingkan dengan sebelum akuisisi dilakukan.

Berdasarkan pembahasan diatas dapat ditarik suatu hasil bahwa manajemen laba pada dua perusahaan pengakuisisi (ANTM dan UNTR) dilakukan dengan menaikkan laba perusahaan (income increasing accruals) sebelum melakukan akuisisi. Dan tiga perusahaan lainnya (ENRG, RAJA, dan SMGR) melakukan manajemen laba dengan menurunkan laba perusahaan (income decreasing accruals) sebelum melakukan akuisisi.

Untuk kinerja keuangannya terbukti bahwa terdapat perbedaan kinerja keuangan perusahaan pengakuisisi se-belum dan sesudah akuisisi yaitu lebih kearah penurunan kinerja keuangan. Kinerja keuangan yang diukur dengan ROA (ANTM, UNTR, SMGR) dan TATO (ANTM, ENRG, UNTR, SMGR) mengalami penurunan sesudah akuisisi. Sedangkan kinerja keuangan yang diukur dengan NPM (ANTM, ENRG, RAJA) dan DER (ANTM, RAJA, SMGR) mengalami peningkatan sesudah akuisisi.

Ada hasil penelitian yang sejalan dengan penelitian ini yaitu penelitian Lia Aisa dan Indarto (2012) yang me-nyebutkan bahwa ada indikasi manajemen laba di sekitar merger dan akuisisi dan kinerja keuangan yang diukur dengan $\mathrm{CR}$, DER, ROI, ROE tidak menunjukkan perbedaan yang signifikan namun NPM dan TATO terdapat perbedaan yang signifikan sebelum dan sesudah merger dan akuisisi.

\section{SIMPULAN}

Penelitian ini membuktikan bahwa manajemen laba pada dua perusahaan pengakuisisi (ANTM dan UNTR) dilakukan dengan menaikkan laba perusahaan (income increasing accruals) sebelum melakukan akuisisi. Sedangkan tiga perusahaan lainnya (ENRG, RAJA, dan SMGR) terbukti melakukan mana-jemen laba dengan menurunkan laba perusahaan (income decreasing accruals) sebelum melakukan akuisisi.

Penelitian ini membuktikan bahwa kinerja keuangan perusahaan pengakuisisi sebelum dan sesudah akuisisi adalah berbeda dan lebih kearah penurunan kinerja keuangan. Kinerja keuangan yang diukur dengan ROA dan TATO mengalami penurunan sesudah akuisisi. Sedangkan NPM dan DER mengalami peningkatan sesudah akuisisi.

\section{DAFTAR PUSTAKA}

Abdul Moin. 2007. Merger, Akuisisi \& Divestasi. Edisi kedua, Cetakan Kedua, EKONISIA, Yogyakarta.

Adnyana Usadha, I Putu dan Gerianta Wirawan Yasa. 2008. "Analisis Manajemen Laba dan Kinerja Keuangan Perusahaan Pengakuisisi Sebelum dan Sesudah Merger dan Akuisisi Di Bursa Efek Indonesia" .Jurnal FakultasEkonomi, Universitas Udayana, Denpasar

Arikunto, S. 2010. Prosedur penelitian : Suatu Pendekatan Praktik. 
(Edisi Revisi). Jakarta : Rineka Cipta

Brigham, E.F and Houston Joel F. 2001. Manajemen Keuangan. Edisi Kedelapan, Penerbit: Erlangga, Jakarta.

Dechow, Patricia M. Et al. 1995. Detecting Earnings

Management. The Accounting Review, April Vol. 70 No. 2.

Dwi Astuti, Christina. Dan Hasnawati. 2003. Analisis pengungkapan Tema-tema Sosial Pada Industri Customer Goods Yang Terdaftar Di BEJ (BungaRampai Penelitian Akuntansi). Jakarta: LPFETrisakti.

Healy, P.M., and Wahlen, J. M., 1998, "A Review of the Earnings Management Literature and Its Implications for Standard Setting", Accounting Horizons, December; 13, 4: 365. Retrieved: February 3rd, 2007, from ProQuest database.

Hitt, Michael A., Harisson, Jeffrep S., Ireland, R. Dvane. 2002. Merger dan Akuisisi Panduan Meraih Laba Bagi Para Pemegang Saham. Jakarta: PT. Raja Graffindo Persada.

Husnan, Suad. 1998. Dasar-dasar Teori Portofolio dan Analisis Sekuritas. Edisi Kedua. Yogyakarta: UPP-AMP YKPN.

Indarto dan Lia Aisa. 2012. Analisis manejemen laba dan kinerja keuangan Sebelum dan sesudah merger dan akuisisi pada Perusahaan pengakuisisi yang terdaftar di Bursa Efek Indonesia tahun 2007-2009. Universitas Semarang. Skripsi.

Kusuma, Hadri dan Wigna Ayu Udiana Sari. 2003. "Manajemen laba oleh perusahaan pengakuisisi sebelum dan sesudah merger dan akuisisi di Indonesia". Jurnal Akutansi dan Auditing Indonesia Vol. 7 No. 1

Lestari, Novi Puji. 2011. Analisis manajemen laba dan kinerja keuangan perusahaan pengakuisisi sebelum dan sesudah akuisisi. Universitas Muhammadiyah Malang.Tesis.

Metta, Anissa. 2010. Analisis manajemen laba dan kinerja perusahaan pengakuisisi sebelum dan sesudah merger dan akuisisi. Universitas Diponegoro.Sripsi.

Scott, William R. 1997. Financial Accounting Theory. International Edition. New Jersey: Prentice-Hall, Inc

Scott, William R. 2000. Financial Accounting Theory. Second Edition. Canada. Prentice Hall.

Scott, William R. 2003. Financial Accounting Theory. Third Edition.University of Waterloo.

Scott, William R. 2009. Financial Accounting Theory. 5nd Ed. Prentice Hall Canada Inc.

J., Liza, A. 2011. Creative Accounting (Mengungkap Manajemen Laba dan Skandal Akuntansi). Jakarta: Salemba Empat.

Sulistyanto, H Sri. 2008. Manajemen Laba: Teori dan Model Empiris. Jakarta: PT

Gramedia Widiasarana Indonesia

Wibowo, Fairuz Angger. 2012. Analisis Perbandingan Kinerja Keuangan Perusahaan Sebelum dan Sesudah Merger dan 
Akuisisi. Universitas Diponegoro. skripsi.

Widyaningdyah, Agnes Utari. 2001. Analisis Faktor-faktor Yang Berpengaruh Terhadap Earnings Management Pada Perusahaan Go Public di Indonesia. Jurnal Akuntansi \&
Keuangan, November Vol. 3 No. 2.

www.ebursa.com.Desember, 14,2014. www.idx.co.id. November, 2, 2014. www.sahamoke.com.Desember, 15,201 4 